\title{
Carbon monoxide-releasing molecule-3 protects against ischemic stroke by suppressing neuroinflammation and alleviating blood-brain barrier disruption
}

Jianping Wang ${ }^{1 *+} \mathbb{D}$, Di Zhang ${ }^{1+}$, Xiaojie Fu', Lie Yu', Zhengfang Lu', Yufeng Gao ${ }^{1}$, Xianliang Liu', Jiang Man ${ }^{1}$, Sijia Li', Nan Liं ${ }^{2,3}$, Xuemei Chen ${ }^{4}$, Michael Hong ${ }^{3}$, Qingwu Yang ${ }^{5}$ and Jian Wang ${ }^{3,4^{*}}$

\begin{abstract}
Background: At low levels, carbon monoxide (CO) has been shown to have beneficial effects on multiple organs and tissues through its potential anti-inflammatory, anti-apoptotic, and anti-proliferative properties. However, the effect of CO-releasing molecule (CORM)-3, a water-soluble CORM, on ischemic stroke and its mechanism of action are still unclear.

Methods: We investigated the role of CORM-3 in the mouse model of transient middle cerebral artery occlusion (tMCAO). CORM-3 or saline was administered to mice by retro-orbital injection at the time of reperfusion after 1-h tMCAO or at $1 \mathrm{~h}$ after sham surgery. We assessed infarct volume and brain water content at 24 and $72 \mathrm{~h}$ after ischemia, blood-brain barrier permeability at 6 and $72 \mathrm{~h}$ after ischemia, and neurologic deficits on days 1, 3, 7, and 14 .

Results: Among mice that underwent $\mathrm{IMCAO}$, those that received CORM- 3 had significantly smaller infarct volume and greater expression of neuronal nuclear antigen (NeuN) and microtubule-associated protein 2 than did salinetreated mice. CORM-3-treated mice had significantly fewer activated microglia in the peri-infarction zone than did control mice and exhibited downregulated expression of ionized calcium-binding adapter molecule (lba)-1, tumor necrosis factor- $a$, and interleukin $1 \beta$. CORM-3-treated mice had significantly lower brain water content and enhanced neurologic outcomes on days 3, 7, and 14 post-tMCAO. Lastly, CORM-3 treatment reduced Evans blue leakage; increased expression of platelet-derived growth factor receptor- $\beta$, tight junction protein ZO-1, and matrix protein laminin; and decreased protein level of matrix metalloproteinase-9.

Conclusion: CORM-3 treatment at the time of reperfusion reduces ischemia-reperfusion-induced brain injury by suppressing neuroinflammation and alleviating blood-brain barrier disruption. Our data suggest that CORM-3 may provide an effective therapy for ischemic stroke.
\end{abstract}

Keywords: Carbon monoxide-releasing molecule-3, Cerebral ischemia, Blood-brain barrier, Neuroinflammation, Carbon monoxide

\footnotetext{
* Correspondence: wjpwfy666@126.com; jwang79@jhmi.edu

†Jianping Wang and Di Zhang contributed equally to this work.

${ }^{1}$ Department of Neurology, The First Affiliated Hospital of Zhengzhou

University, Zhengzhou 450052, Henan, China

${ }^{3}$ Department of Anesthesiology/Critical Care Medicine, Johns Hopkins

University, School of Medicine, Baltimore 21205, MD, USA

Full list of author information is available at the end of the article
}

(c) The Author(s). 2018 Open Access This article is distributed under the terms of the Creative Commons Attribution 4.0 International License (http://creativecommons.org/licenses/by/4.0/), which permits unrestricted use, distribution, and reproduction in any medium, provided you give appropriate credit to the original author(s) and the source, provide a link to the Creative Commons license, and indicate if changes were made. The Creative Commons Public Domain Dedication waiver (http://creativecommons.org/publicdomain/zero/1.0/) applies to the data made available in this article, unless otherwise stated. 


\section{Background}

Ischemic stroke is the most common form of stroke and a major cause of disability and death in adults worldwide. The obstruction of cerebral blood flow initiates the acute phase of cerebral injury, including neuroinflammation and cerebral edema [1]. Neuroinflammation is a crucial contributor to neuronal death after ischemic stroke, and activated microglia have been the object of studies concentrating on neuroinflammation [2-5]. Cerebral edema, mainly resulting from the increase of cerebral vascular permeability, is the most common cause of neurologic deficiency and mortality during acute ischemic stroke, highlighting the importance of maintaining blood-brain barrier (BBB) integrity [6-9]. Despite enormous efforts in both preclinical and clinical research, treatments to protect against ischemic stroke are still insufficient.

A novel approach to protecting against ischemic stroke injury is the administration of low levels of exogenous $\mathrm{CO}$ [10]. Endogenous carbon monoxide $(\mathrm{CO})$ is a product of heme catabolism by heme oxygenase (HO) [11-14]. Exogenous $\mathrm{CO}$ is commonly regarded as poisonous because its high affinity for hemoglobin can cause rapid elevation of carboxyhemoglobin $(\mathrm{COHb})$ to toxic levels that compromise oxygen delivery to the tissues [11]. However, accumulating evidence suggests that low levels can offer protection through potential anti-inflammatory, antiapoptotic, and anti-proliferative effects [15-17]. Carbon monoxide-releasing molecules (CORMs), a group of compounds capable of carrying and liberating controlled quantities of $\mathrm{CO}$, have shown promise for delivering exogenous $\mathrm{CO}$ without altering $\mathrm{COHb}$ to toxic levels $[11,18-20]$. Although the mechanisms by which CORM-derived $\mathrm{CO}$ might offer its beneficial effects have not yet been thoroughly investigated, many studies substantiate the protective role of CORM-derived $\mathrm{CO}$ against cellular and tissue damage in numerous models of injury, such as renal ischemia-reperfusion injury, hemorrhagic stroke, traumatic brain injury, transplantation, sepsis, hypertension, and cardiovascular disorders [21-28].

Currently, the effect of water-soluble CORM-3 $[11,22,24]$ on ischemic stroke remains unclear. In this study, we investigated the therapeutic potential of CORM-3 for ischemic stroke using a mouse model of transient middle cerebral artery occlusion (tMCAO). We found that CORM-3 treatment may contribute to better outcomes after cerebral injury by attenuating brain infarct and edema, lessening BBB disruption, and improving neurologic functions. Further investigation into mechanisms underlying the beneficial effects of CORM-3 on ischemic stroke revealed that CORM-3 increased the protein levels of neuronal nuclear antigen (NeuN) and microtubule-associated protein 2 (MAP2), and suppressed microglial activation, which reduced the quantities of reactive microglia and downregulated the expression of ionized calcium-binding adapter molecule (Iba)-1, tumor necrosis factor (TNF)- $\alpha$, and interleukin (IL) $1 \beta$. CORM-3 also elevated the expression of the pericyte marker platelet-derived growth factor receptor (PDGFR)- $\beta$, tight junction protein $\mathrm{ZO}-1$, and matrix protein laminin, which reduced $\mathrm{BBB}$ leakage. Finally, CORM-3 reduced the protein level of matrix metalloproteinase (MMP)-9. Taken together, our findings demonstrate clear benefits of CORM-3 on ischemic stroke through suppression of neuroinflammation and alleviation of BBB disruption.

\section{Methods}

\section{Animals}

We purchased adult, male C57BL/6 mice (12-14 weeks old, 25-30 g) from the Animal Experimental Center of Zhengzhou University. Efforts were made to minimize the number of animals used and their suffering.

\section{Transient middle cerebral artery occlusion model}

We subjected mice to the tMCAO model of ischemic stroke as previously described [29-31]. We briefly anesthetized each mouse with an intraperitoneal injection of $5 \%$ chloral hydrate, made a midline neck incision, and carefully separated the arteries from adjacent tissues. Then, we introduced a 6.0 monofilament nylon suture with silicone-coated tip into the origin of the middle cerebral artery and left it in place for $60 \mathrm{~min}$ before withdrawing it. We defined a successful tMCAO as an approximately $80 \%$ decrease in cerebral blood flow confirmed by laser Doppler flowmetry (Moor Instruments, Devon, UK). Mice in the sham group were subjected to an identical surgical procedure, except that the filament was advanced to the origin of the middle cerebral artery and withdrawn immediately.

\section{Experimental groups}

We randomly [32] assigned the animals to four groups: (1) sham mice treated with saline (Sham + saline, $n=72$ ),

(2) tMCAO-operated mice treated with saline (tMCAO + saline, $n=82$ ), (3) sham mice treated with CORM-3 (Sham + CORM-3, $n=72$ ), and (4) tMCAO-operated mice treated with CORM-3 (tMCAO + CORM-3, $n=82)$. We administered saline (vehicle) or CORM-3 (Sigma-Aldrich, St. Louis, MO, USA) dissolved in saline $(4 \mathrm{mg} / \mathrm{kg}$ body weight) by retro-orbital injection at the time of reperfusion or $1 \mathrm{~h}$ after sham surgery $[24,33]$. We examined mice for infection or illness daily.

\section{Cerebral infarct volume determination}

We determined the brain infarct volume on days 1 and 3 after tMCAO as previously described [29, 34]. We 
sliced each brain into four, 2-mm-thick, coronal sections with a mouse brain matrix slicer (Stoelting Instruments, Wood Dale, IL, USA). The sections were immersed into 2\% 2,3,5-triphenyltetrazolium chloride (TTC; Sigma-Aldrich) for $30 \mathrm{~min}$ at $37^{\circ} \mathrm{C}$ and fixed in $4 \%$ paraformaldehyde in phosphate-buffered saline (PBS) overnight. Normal tissue stained red, whereas the infarct area remained white. We used Image J software $(\mathrm{NIH}, \mathrm{Be}-$ thesda, MD, USA) to measure the infarct area on the posterior surface in each brain slice by subtracting the intact area of the ipsilateral hemisphere from the total area of the contralateral hemisphere to correct for brain swelling. We then calculated the total infarct volume by linear integration of the corrected lesion areas [9]. We calculated the infarct volume percentage with the formula: total infarct volume/contralateral hemisphere volume $\times 100 \%$.

\section{Evaluation of BBB permeability}

For analysis of BBB permeability at 6 and $72 \mathrm{~h}$ post-surgery $[9,35]$, we injected each mouse with $100 \mu \mathrm{l}$ of $4 \%$ Evans blue dye (dissolved in saline; Sigma-Aldrich) by retro-orbital injection. Two hours later, we perfused the mouse transcardially with saline, removed the brain, and separated it into ipsilateral and contralateral hemispheres. Each hemisphere was homogenized in $N, N$-dimethylformamide (Sigma-Aldrich) and centrifuged for $50 \mathrm{~min}$ at 14,000 rpm. We collected the supernatants and quantified Evans blue extravasation with the formula: $\left(A_{620 \mathrm{~nm}}-\left(\left(A_{500 \mathrm{~nm}}+A_{740 \mathrm{~nm}}\right) / 2\right)\right)$ per gram wet weight. We subtracted background Evans blue level in the contralateral hemisphere from that of the ipsilateral hemisphere $[8,24]$. For qualitative assessment of Evans blue extravasation at $72 \mathrm{~h}$, we fixed the brains in $4 \%$ paraformaldehyde and cut $20-\mu \mathrm{m}$-thick sections. We mounted the sections on cover slips with a drop of mounting medium containing $1.5 \mu \mathrm{g} / \mathrm{ml}$ 4',6-diamidino-2-phenylindole (DAPI; Santa Cruz Biotech, Dallas, TX, USA) and observed them under a fluorescence microscope (ZEISS Scope A1, ZEISS, Germany) [36].

\section{Assessment of brain water content}

We sacrificed the mice on days 1 and 3 after tMCAO to determine the brain water content as previously described $[30,37]$. The brain was divided into two hemispheres from the anatomic midline. The right hemisphere was immediately weighed with an electronic analytical balance to obtain the wet weight. The dry weights were obtained after the brain samples were dried at $100{ }^{\circ} \mathrm{C}$ in an oven for $24 \mathrm{~h}$. We determined the brain water content with the following formula: (wet weight - dry weight)/wet weight $x$ $100 \%$ [38].

\section{Neurologic assessment}

An investigator blinded to the treatment groups tested the mice on days $1,3,7$, and 14 after surgery for neurologic deficits using a five-point scale [8]: $0=$ no neurologic deficit, 1 = failure to fully extend left forepaw, $2=$ circling to the contralateral side, $3=$ falling to the left, $4=$ no spontaneous walking, 5 = depressed level of consciousness.

\section{Immunofluorescence}

We sacrificed mice on day 3 after surgery for immunofluorescence analysis as previously described [30, 31, 39]. Briefly, mice were anesthetized with an intraperitoneal injection of $5 \%$ chloral hydrate and perfused with PBS and $4 \%$ paraformaldehyde. We carefully removed the brains, fixed them in $4 \%$ paraformaldehyde overnight at $4{ }^{\circ} \mathrm{C}$, and then immersed them in $30 \%$ sucrose/PBS until they sank. Coronal sections $(20 \mu \mathrm{m})$ were obtained by cryoultramicrotomy (CM1100, Leica Biosystems, Germany). After being washed in PBS, the sections were incubated in PBST $(0.3 \%$ Triton X-100 in PBS), blocked in $1 \%$ bovine serum albumin (BSA)/ PBST, and subsequently incubated with the following primary antibodies overnight at $4{ }^{\circ} \mathrm{C}$ : goat anti-Iba1 (1:1000, Abcam, Cambridge, MA, USA), rat antiCD31 (1:500, Abcam), rabbit anti-ZO-1 (1:150, Proteintech, Sanying Biotechnology, Wuhan, China), rabbit anti-laminin $(1: 1000$, Novus Biologicals, Littleton, CO, USA), rat anti-PDGFR $\beta$ (1:1000, Abcam), rabbit anti-MMP-9 (1:1000, Abcam). All antibodies were diluted in $1 \%$ BSA/PBST. Then, sections were washed in PBS and incubated with appropriate secondary antibodies for $1 \mathrm{~h}$ at room temperature in the dark. The sections were finally washed in PBS and mounted on cover slips with a drop of DAPI (Santa Cruz). Using a fluorescence microscope (ZEISS), an investigator blinded to the experimental groups randomly chose three separate tissue sections of each mouse and three non-overlapping $20 \times$ fields in the peri-infarction zone to quantify the number of activated microglia, the ZO-1-positive area/CD31-positive area, the laminin-positive area/CD31-positive area, and the number of PDGFR $\beta / M M P-9-$ positive cells. Activated microglia were defined as $\mathrm{Iba}^{+}$cells with a rod-like, spherical, or amoeboid appearance, and a cell body more than $10 \mu \mathrm{m}$ in diameter that had short, thick processes and intense immunoreactivity, as we previously described $[40,41]$.

\section{Western blot analysis}

We sacrificed the mice on day 3 after surgery for Western blot analysis as previously described [31, 40]. Protein was extracted from the whole right hemisphere, separated on $6-12 \%$ glycine gels, and transferred onto 
polyvinylidene difluoride membranes (Millipore, Bedford, MA). Membranes were blocked in 5\% nonfat milk in Tris-buffered saline (TBS) with $0.1 \%$ Tween-20 (TBST) for $1 \mathrm{~h}$ at room temperature and stained overnight at $4{ }^{\circ} \mathrm{C}$ with one of the following primary antibodies: rabbit anti-NeuN (1:1000, Abcam), rabbit anti-MAP2 (1:200, Proteintech), rabbit anti-glyceraldehyde-3-phosphate dehydrogenase (GAPDH; 1:2000, Proteintech), goat anti-Iba-1 (1:1000, Abcam), rabbit anti-TNF- $\alpha$ (1:1000, Cell Signaling Technology, Danvers, MA, USA), rabbit anti-IL1 $\beta$ (1:200, Proteintech), rabbit anti-ZO-1 (1:200, Proteintech), rabbit anti-laminin (1:1000, Novus Biologicals), rat anti-PDGFR $\beta$ (1:1000, Abcam), rabbit antiMMP-9 (1:50, Santa Cruz). These antibodies were diluted in $5 \%$ nonfat milk/TBST. We washed these membranes with TBST and incubated them with appropriate secondary antibodies conjugated to horseradish peroxidase for $2 \mathrm{~h}$ at room temperature. Protein bands were visualized by enhanced chemiluminescence detection kit (CW Biotech, Beijing, China), and an investigator blinded to the animal group quantified the optical density of the protein bands using Gel Analysis V 2.02 software (Clinx Science Instruments, Shanghai, China). GAPDH served as a loading control.

\section{Enzyme-linked immunosorbent assay (ELISA) analysis}

We sacrificed the mice on day 3 post-surgery and prepared the brain homogenates for ELISA as previously described [31]. We homogenized the right hemisphere using a protein extraction kit (Sangon Biotech, Shanghai, China) and measured protein concentration with a bicinchoninic acid protein assay kit (Sangon Biotech). We adjusted the total protein concentration to $1 \mathrm{mg} / \mathrm{ml}$ protein extract and quantified the concentrations of TNF- $\alpha$ and IL1 $\beta$ in brain homogenates according to the manufacturer's protocol (Boster, Wuhan, China).

\section{Statistical analysis}

We performed statistical analysis with SPSS version 13.0. Results are expressed as mean $\pm \mathrm{SD}$. We used repeated measures ANOVA to determine changes in neurologic deficit score after tMCAO. Student's $t$ test or one-way ANOVA followed by the least significant difference test was used to analyze differences in data from infarction volume, brain water content, Evans blue dye leakage, Western blot analysis, ELISA analysis, and immunofluorescence. Differences were considered statistically significant at $p<0.05$.

\section{Results}

CORM-3 treatment reduces cerebral infarct volume and increases protein levels of NeuN and MAP2 after tMCAO TTC staining showed that the infarct volume of the $\mathrm{tMCAO}+$ saline group was significantly larger than that of the tMCAO + CORM-3 group on days 1 and 3 after surgery (Fig. 1a-d). Western blot analysis revealed that the expression levels of NeuN and MAP2 were significantly lower in the tMCAO + saline group than in the Sham + saline group on day 3. The CORM-3-treated tMCAO group had significantly higher levels of NeuN and MAP2 than did the saline-treated tMCAO group on day 3 after brain ischemia. Additionally, the protein levels of NeuN and MAP2 did not differ significantly between the Sham + saline group and the Sham + CORM-3 group (Fig. 1e-g).

\section{CORM-3 treatment decreases the number of activated microglia and the expression of Iba-1, TNF- $a$, and IL1 $\beta$ after $\mathrm{tMCAO}$}

In comparison with saline-treated tMCAO mice, CORM-3-treated tMCAO mice had significantly fewer activated microglia in the peri-infarction zone on day 3 after ischemia (Fig. 2a-c), a finding that was confirmed by the concomitant reduction in Iba- 1 protein expression (Fig. 2d, e). Expression levels of pro-inflammatory cytokines TNF- $\alpha$ and IL1 $\beta$ were significantly higher in the tMCAO + saline group than that in the Sham + saline group, but CORM-3 significantly prevented this increase, as evidenced by Western blot results on day 3 after surgery. Levels of both TNF- $\alpha$ and IL1 $\beta$ were similar between the saline-treated and CORM-3-treated sham groups (Fig. 2d, f-i).

CORM-3 treatment reduces brain water content and neurologic deficits after tMCAO.

On days 1 and 3 after the ischemic insult, we found that saline-treated $\mathrm{MCCAO}$ mice had higher brain water content than the saline-treated sham mice; however, brain water content was significantly lower in the tMCAO + CORM-3 group than in the tMCAO + saline group. No significant difference was apparent between the Sham + saline and the Sham + CORM-3 groups (Fig. 3a, b). Neurologic deficit scores were elevated after tMCAO and gradually decreased over 2 weeks. Notably, tMCAO mice that received CORM-3 had lower scores on days 3,7 , and 14 than did the saline-treated tMCAO mice (Fig. 3c).

\section{CORM-3 treatment reduces Evans blue leakage after tMCAO}

We evaluated BBB permeability at 6 and $72 \mathrm{~h}$ after surgery by assessing Evans blue extravasation. The results showed that the Evans blue leakage was significantly reduced in the tMCAO + CORM-3 group compared to that in the tMCAO + saline group (Fig. 4a-d). The qualitative assessment of Evans blue extravasation at $72 \mathrm{~h}$ further confirmed the findings (Fig. 4e). 

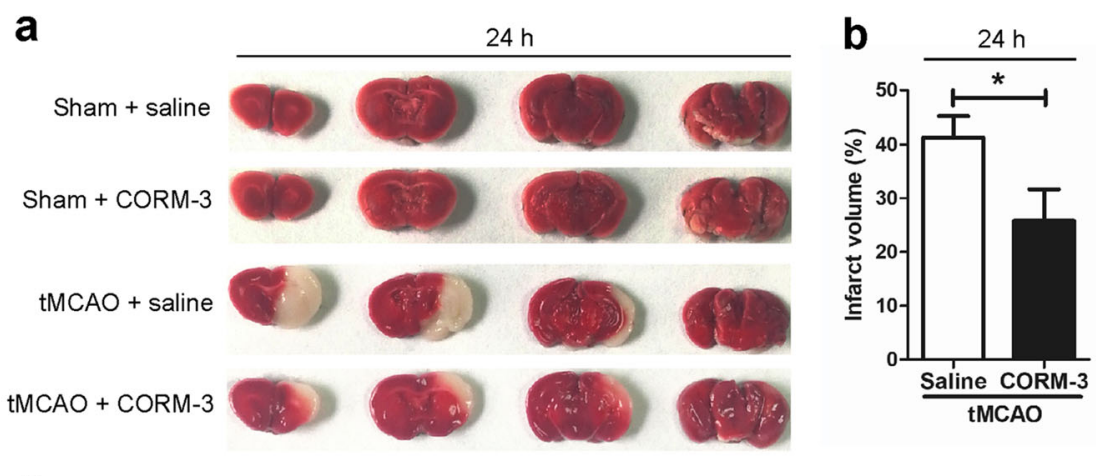

C

Sham + saline

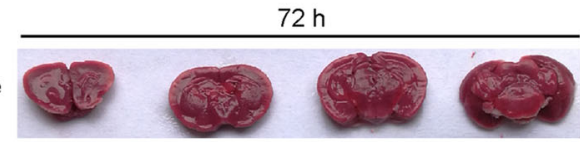

Sham + CORM-3

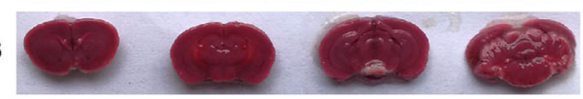

tMCAO + saline

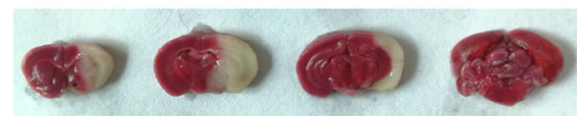

TMCAO + CORM-3
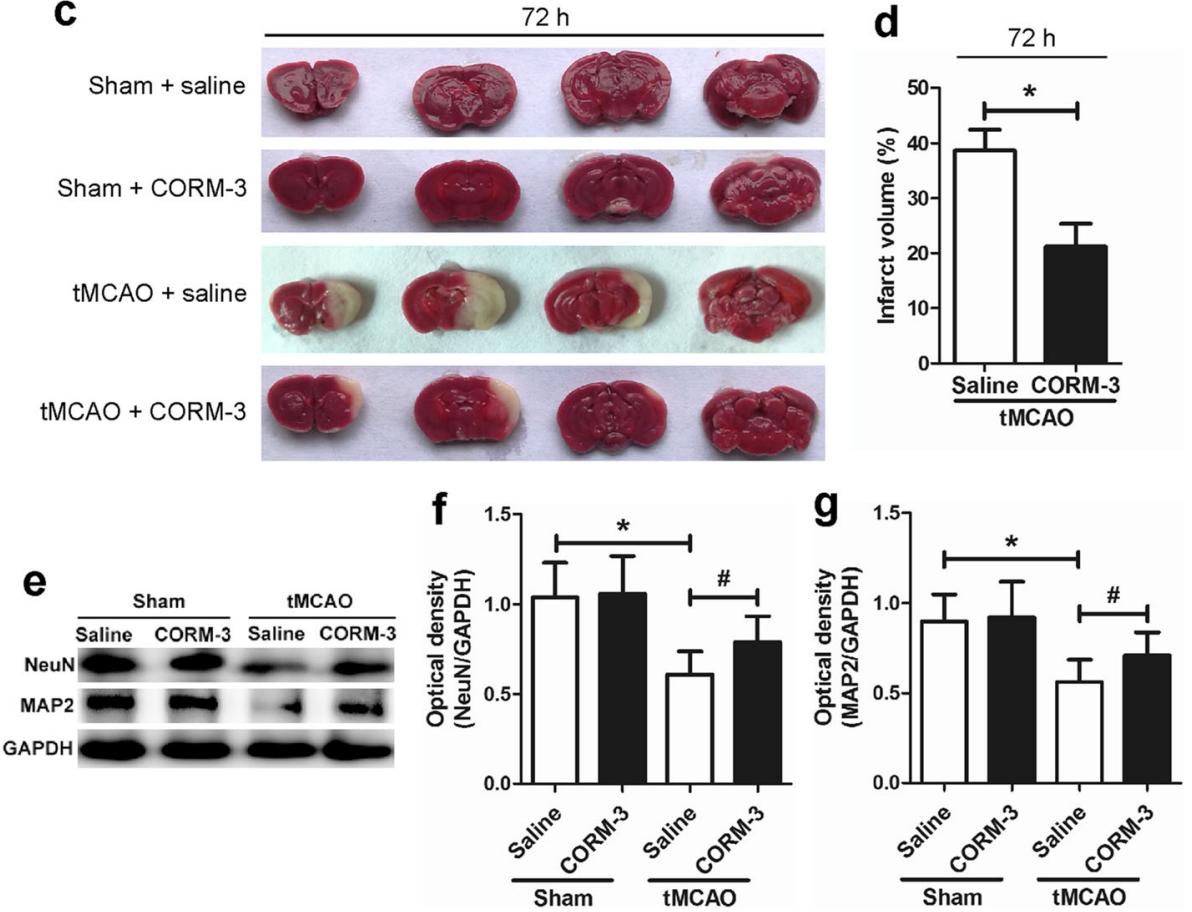

Fig. 1 CORM-3 treatment reduces infarct volume and increases the expression of NeuN and MAP2. a, c Representative TTC staining illustrates the brain infarct volume in each group at $24 \mathrm{~h} \mathrm{(a)} \mathrm{and} 72 \mathrm{~h}$ (c) after tMCAO or sham surgery; areas of infarct remain white. b, d Quantification of TTC staining in the saline- and CORM-3-treated tMCAO groups at $24 \mathrm{~h} \mathrm{(b)} \mathrm{and} 72 \mathrm{~h}(\mathbf{d})$ after tMCAO. Values represent corrected infarct volume as a percentage of the contralateral area ( ${ }^{*} p<0.05, n=6$ per group). e Representative Western blot analysis of NeuN and MAP2 in the right hemisphere of each group. $\mathbf{f}, \mathbf{g}$ Quantification of the Western blot analysis $\left({ }^{*} p<0.05\right.$ vs. Sham + saline group, ${ }^{\#} p<0.05$ vs. tMCAO + CORM-3 group, $n=10$ per group). Data are shown as mean \pm SD

\section{CORM-3 treatment increases the expression of ZO-1 and} laminin after $\mathrm{tMCAO}$

Immunofluorescence staining showed that CORM-3treated tMCAO mice had more ZO-1-positive or laminin-positive vessels (labeled by CD31) in peri-infarction regions than did saline-treated tMCAO mice on day 3 post-surgery (Fig. 5a-d). Western blot analysis showed that expression levels of ZO-1 and laminin were significantly higher in the CORM-3-treated tMCAO mice than in the saline-treated $\mathrm{tMCAO}$ mice. However, the expression of neither protein differed significantly between the saline-treated and CORM-treated sham mice (Fig. 5e-g).
CORM-3 treatment increases the expression of PDGFR $\beta$ and decreases the expression of MMP-9 after $\mathrm{TMCAO}$

We detected the expression of PDGFR $\beta$ and MMP-9 in the ischemic hemisphere by using immunofluorescence staining and Western blot analysis on day 3 after surgery. The tMCAO + CORM-3 group had significantly fewer PDGFR $\beta /$ MMP-9-positive cells in peri-infarction areas than did the tMCAO + saline group (Fig. 6a, b). The tMCAO + saline group had significantly lower expression of pericyte marker PDGFR $\beta$ and greater expression of MMP-9 than did the Sham + saline group. On the other hand, the tMCAO + CORM-3 group had significantly higher expression of PDGFR $\beta$ and lower 

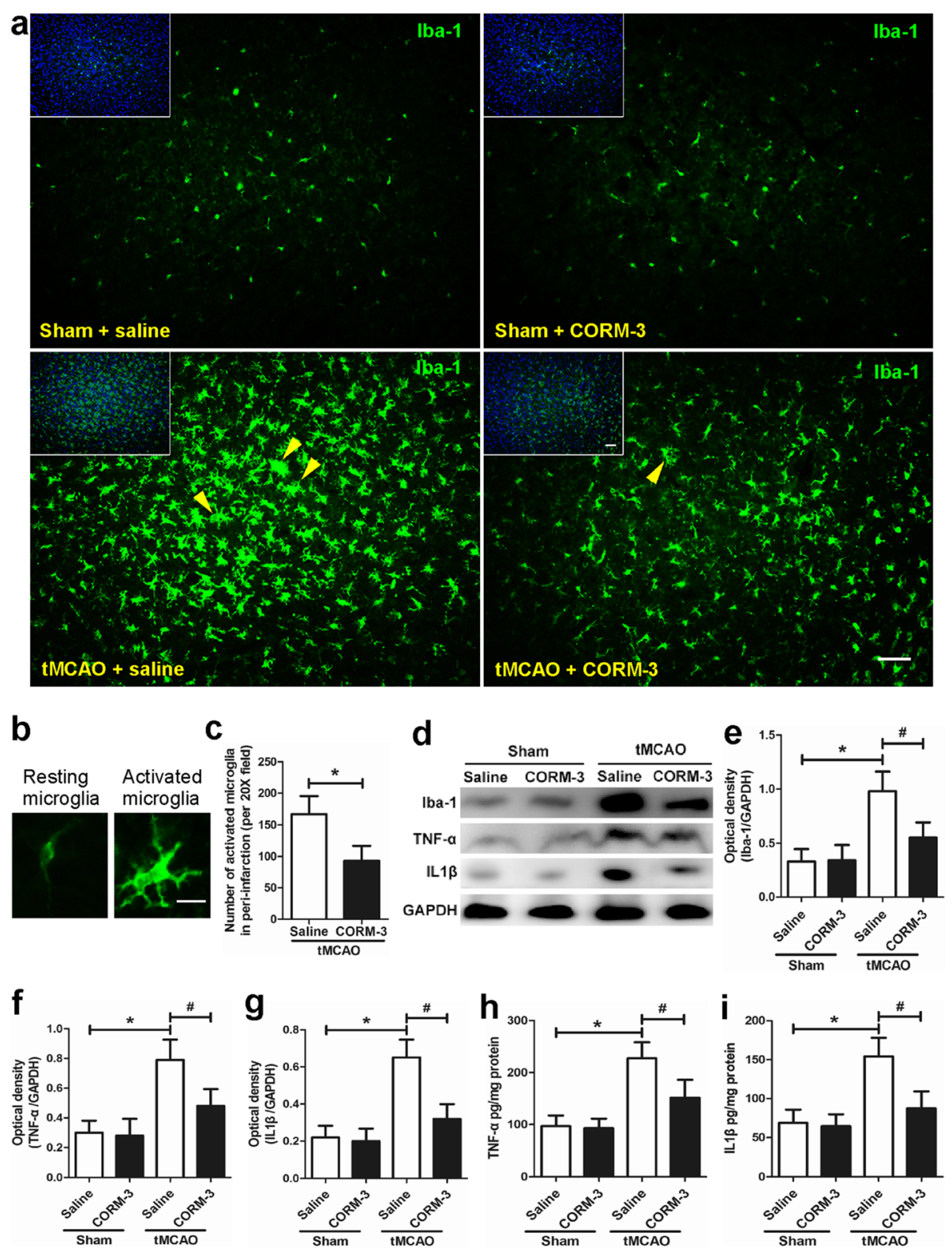

Fig. 2 CORM-3 treatment decreased the number of activated microglia at 3 days after ischemia. a Representative immunofluorescence staining of Iba-1-positive cells in each group. Insets show colocalization of the nuclear stain DAPI (blue). Yellow arrowheads point out activated microglia in peri-infarction zones. Scale bar $=50 \mu \mathrm{m}$. b Representative images show the morphology of resting (left) and activated (right) microglia. Scale bar $=10 \mu \mathrm{m}$. c Quantification indicates that CORM-3 significantly decreased the number of activated microglia $\left({ }^{*} p<0.05, n=8\right.$ per group). $\mathbf{d}$ Representative Western blot of Iba-1, TNF-a, and IL1 $\beta$ expression. e- $\mathbf{g}$ Quantification of the Western blot analysis $\left({ }^{*} p<0.05\right.$ vs. Sham + saline group, ${ }^{\#} p<0.05$ vs. tMCAO + CORM-3 group, $n=10$ per group). $\mathbf{h}, \mathbf{i}$ ELISA analysis of TNF-a and IL1 $\beta$ ( ${ }^{*} p<0.05$ vs. Sham + saline group, $" p<0.05$ vs. tMCAO + CORM-3 group, $n=8$ per group). Data are shown as mean \pm SD

expression of MMP-9 when compared with levels in the tMCAO + saline group. There were no differences in the protein levels between Sham + saline and Sham + CORM-3 groups (Fig. 6c-e).

\section{Discussion}

Our findings suggest that CORM-3 has a protective effect in a mouse model of ischemic stroke injury. We found that CORM-3 treatment reduced infarct volume and brain water content, alleviated BBB disruption, and promoted neurologic recovery after ischemic stroke. Furthermore, CORM-3 increased the protein levels of NeuN and MAP2, reduced microglial activation, decreased the expression of pro-inflammatory cytokines TNF- $\alpha$ and IL1 $\beta$, increased the expression of PDGFR $\beta$, $\mathrm{ZO}-1$, and laminin, and downregulated the protein level 


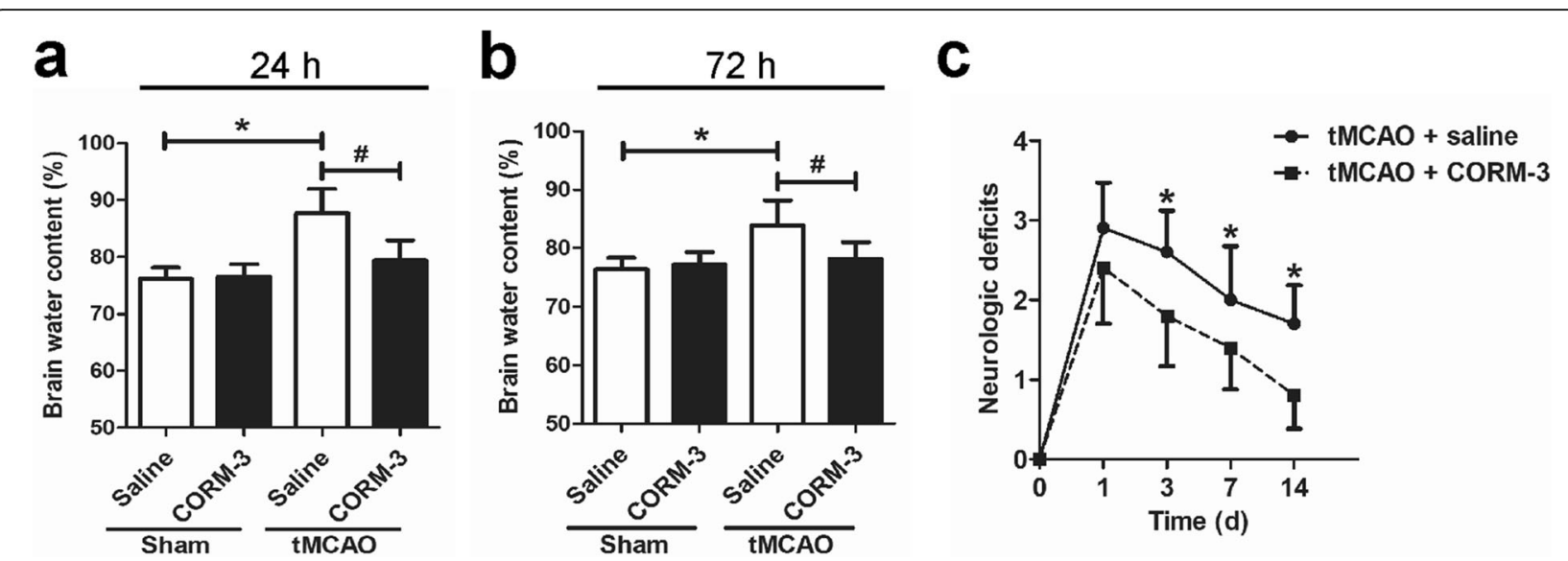

Fig. 3 Assessments of brain water content and neurologic deficit. $\mathbf{a}, \mathbf{b}$ Quantification of brain water content in the indicated groups at $24 \mathrm{~h}(\mathbf{a})$ and $72 \mathrm{~h}$ (b) after tMCAO or sham surgery ( ${ }^{*} p<0.05$ vs. Sham + saline group, ${ }^{*} p<0.05$ vs. tMCAO + CORM-3 group, $n=6$ per group). c Neurologic deficits were significantly less in the CORM-3-treated tMCAO mice than in the saline-treated tMCAO mice on days 3, 7, and14 ${ }^{*} p<0.05, n=10$ per group). Data are shown as mean \pm SD

of MMP-9 compared with corresponding levels in saline-treated mice. Our study suggests that CORM-3 ameliorates ischemic stroke injury by suppressing neuroinflammation and alleviating BBB disruption.

Against general dogma that $\mathrm{CO}$ is poisonous, particularly to the brain, accumulating evidence suggests that it might be associated with cytoprotection and maintenance of homeostasis in several organs and tissues $[10,23,27,28,42-44]$. Therefore, exogenous administration of $\mathrm{CO}$ at low levels (as inhaled $\mathrm{CO}$ gas or as CORMs) could be explored as a potential therapeutic method. It has been shown that low levels of inhaled CO provide benefit against ischemia-reperfusion brain injury by attenuating ischemia-induced infarct volume, reducing edema formation, and restoring cerebral blood flow [45]. A study that used a model of permanent ischemic stroke indicated that a low concentration of inhaled $\mathrm{CO}$ provided neuroprotective effect by activating the Nrf2 pathway [46]. However, the application of $\mathrm{CO}$ gas presents several limitations, such as the potential for partial systemic hypoxia and toxicity and the need for $\mathrm{CO}$ inhalation facilities and monitoring of blood oxygen levels [11]. Given these barriers, transition metal carbonyls are good candidates for delivering $\mathrm{CO}$, as they function as CORMs in biological systems [11]. Water-soluble CORM-3 has beneficial effects in many models of injury, such as hemorrhagic stroke, pulmonary hypertension, and ischemia-reperfusion injury during kidney transplantation [21, 22, 47]. However, the effect of CORM-3 on ischemic stroke and its mechanism of protection are still unclear. In this study, we treated tMCAO mice with CORM-3 at the time of reperfusion and investigated the therapeutic effects. We used a CORM-3 dose of $4 \mathrm{mg} / \mathrm{kg}$ because of studies showing that this dose releases an amount of $\mathrm{CO}$ in mice that may be sufficient to exert protective effect $[22,24]$. We did not monitor the effects of CORM-3 on the level of $\mathrm{COHb}$ because studies have already indicated that various doses of CORM-3 have no effects on $\mathrm{COHb}$ in mice $[19,20]$. We found that the administration of CORM-3 significantly decreased cerebral infarct volume and water content after ischemic stroke, similar to results from a previous study that used inhaled CO [45]. Additionally, the protein levels of NeuN and MAP2 in the ischemic brain of CORM-3-treated tMCAO mice were significantly increased compared with those of saline-treated controls. NeuN and MAP2 are well recognized as markers of mature neurons. It is likely that CORM-3 increases the levels of these two proteins by decreasing neuronal death or apoptosis, rather promoting neurogenesis, because 3 days is not long enough for neural stem cells in the subventricular zone to proliferate, migrate to the peri-infarction zone, and differentiate into mature neurons [40, 48, 49]. In addition, CORM-3 treatment markedly reduced BBB permeability and promoted neurologic recovery after ischemic stroke. These results suggest that CORM-3 might provide protection against ischemic stroke. Our study focused on the acute phase after ischemia, but it will be important to determine the long-term effects of CORM-3 on post-stroke neurogenesis, angiogenesis, and recovery of ischemic white matter injury.

Upregulation of endogenous neuroinflammatory processes is a crucial secondary cell death mechanism that follows ischemic stroke and initiates a feedback loop of inflammatory cascades that can expand the region of brain damage [1]. Evidence has shown that inflammation not only affects the infarct tissue in the near-term but 

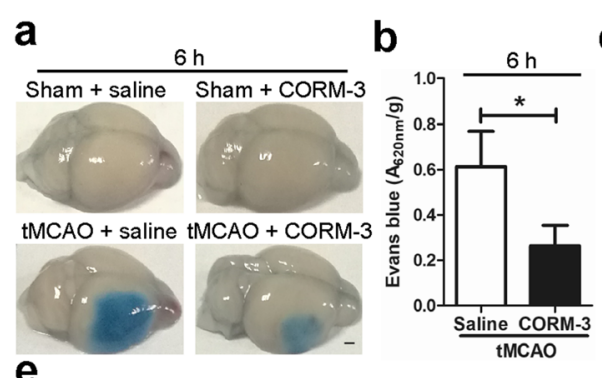

C
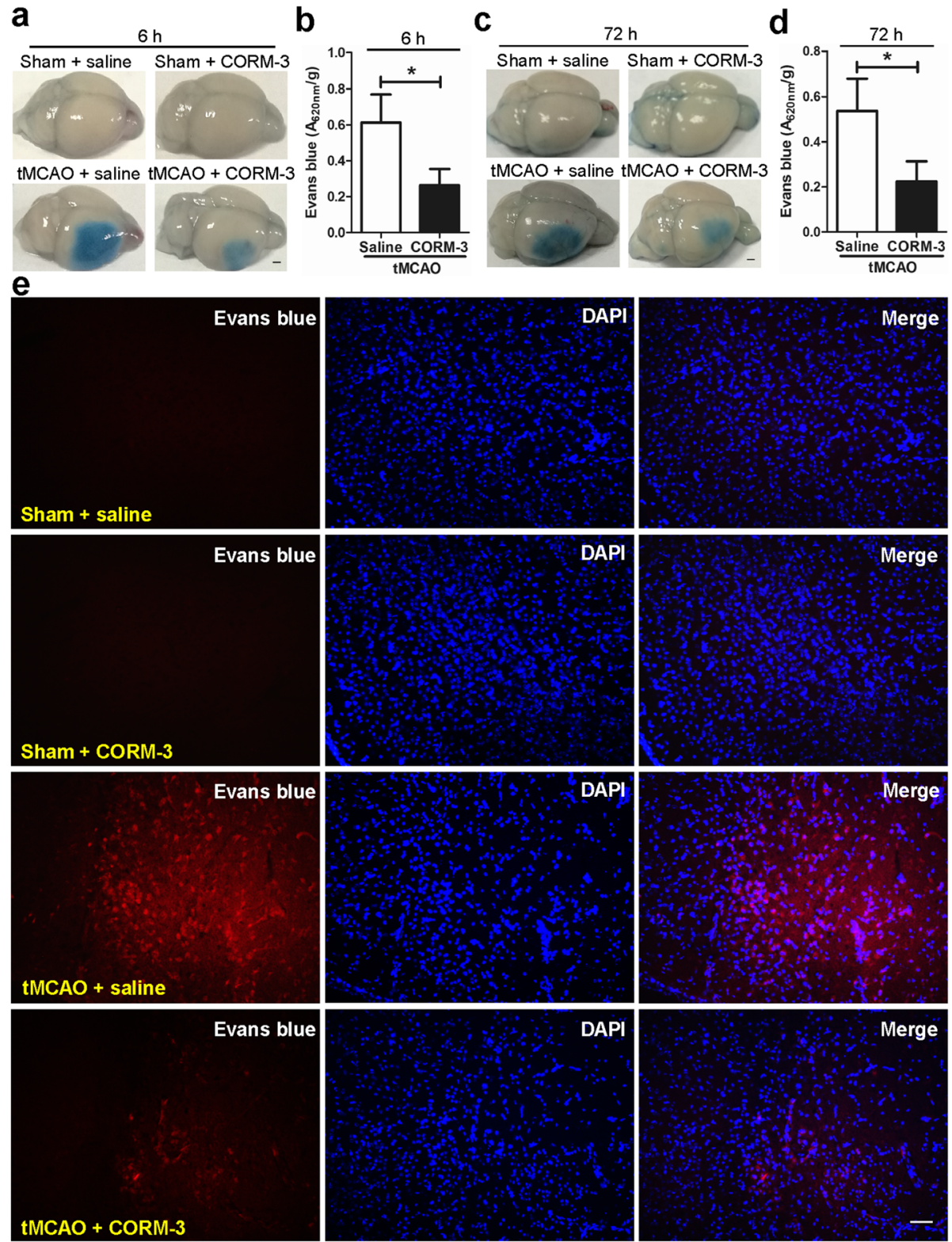

Fig. 4 Assessment of blood-brain barrier dysfunction. a, c Representative brain images show Evans blue leakage at $6 \mathrm{~h}$ (a) and $72 \mathrm{~h}$ (c) post-surgery in each group. Scale bar $=1 \mathrm{~mm}$. b, d Quantitative analysis of Evans blue leakage in tMCAO + saline and tMCAO + CORM-3 groups at $6 \mathrm{~h}(\mathbf{b})$ and $72 \mathrm{~h}$ (d) post-surgery ( ${ }^{*} p<0.05, n=8$ per group, data are shown as mean \pm SD). e Representative fluorescence of Evans blue extravasation in peri-infarction zone at $72 \mathrm{~h}$ post-surgery ( $n=6$ per group). Scale bar $=50 \mu \mathrm{m}$

also causes long-term damage in the ischemic penumbra $[2,4]$. Microglia, the brain's resident immune cells, are rapidly activated from their resting state after ischemic stroke and are considered to be major cellular contributors to neuroinflammation $[50,51]$. Activated microglia initiate neuroinflammation by producing cytotoxic and inflammatory factors, including the cytokines TNF- $\alpha$ and IL- $1 \beta$, thereby aggravating brain damage $[5,52]$. At high concentrations, TNF- $\alpha$ and IL1 $\beta$ have direct toxic effects on neurons and neural cells [53, 54]. Consequently, activated microglia have been the target of studies focusing on neuroinflammation. CORMs possess anti-inflammatory properties, and CORM-3 has been shown to reduce microglial activation in BV-2 microglia and in a rat model of hemorrhagic stroke [22, 55]. To investigate whether CORM-3 regulates neuroinflammation after ischemic stroke, we characterized activated microglia as $\mathrm{Iba}^{+}$cells with special morphology as previously described $[14,40,56]$. We found that the administration of CORM-3 decreased the number of activated microglia in the peri-infarction zone and reduced the expression of Iba-1, TNF- $\alpha$, and IL1 $\beta$ in ipsilateral tissue 

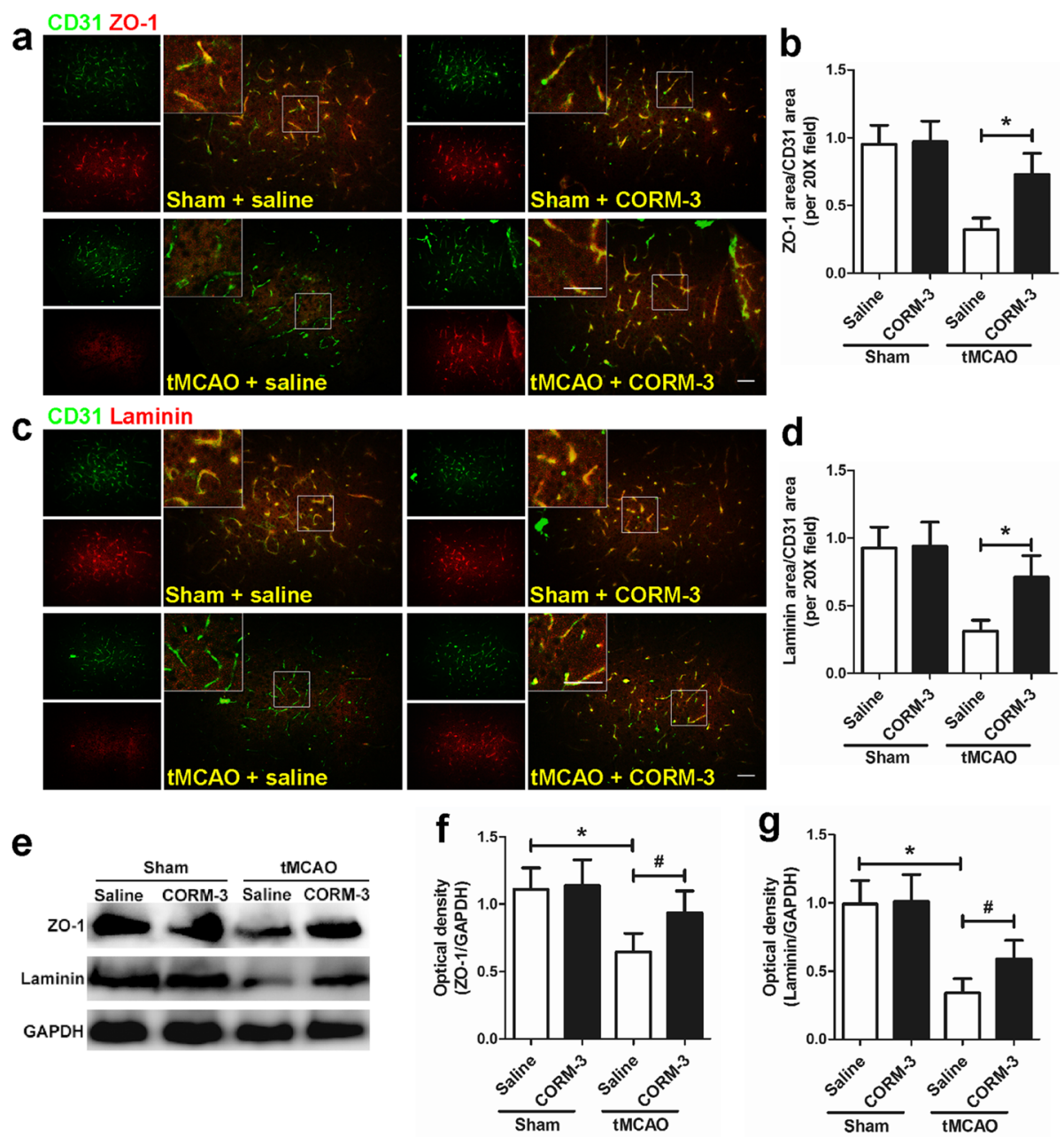

Fig. 5 CORM-3 increases the expression of ZO-1 and laminin on day 3 after cerebral infarction. a Representative images show double immunofluorescence staining of CD31/ZO-1-positive cells in peri-infarction zones. Insets show high-magnification images of the boxed areas. Scale bar $=50 \mu \mathrm{m}$. b Quantification of ZO-1-positive area/CD31-positive area in peri-infarction zones $\left({ }^{*} p<0.05, n=8\right.$ per group). c Representative images show double immunofluorescence staining of CD31/laminin-positive cells in peri-infarction zones. Insets show high-magnification images of the boxed areas. Scale bar $=50 \mu \mathrm{m}$. $\mathbf{d}$ Quantification of laminin-positive area/CD31-positive area in peri-infarction zones $\left(^{*} p<0.05, n=8\right.$ per group). e Representative Western blot of ZO-1 and laminin expression in the right hemisphere of each group. $\mathbf{f}, \mathbf{g}$ Quantification of the Western blot analysis ( ${ }^{*} p<0.05$ vs. Sham + saline group, ${ }^{*} p<0.05$ vs. tMCAO + CORM-3 group, $n=10$ per group). Data are shown as mean \pm SD

at $72 \mathrm{~h}$ after reperfusion. Consistent with the anti-inflammatory effect shown in previous studies, our results indicate that CORM-3 suppressed neuroinflammation after ischemic stroke. We hypothesize that CORM-3 might reduce the release of damage-associated molecular pattern molecules (DAMPs), such as high-mobility group box 1 (HMGB1) and galectin-3 (Gal3) [57], which have been shown to stimulate microglia after ischemic stroke. HMGB1 is released from necrotic neurons and mediates the activation of microglia via Toll-like receptors (TLRs) or the receptor of advanced glycation end-products (RAGE) on microglia [58]. Gal3 is released from microglia, and Gal3-dependent TLR4 activation promotes microglial activation [59]. CORM-3 might directly modulate microglia phenotype by inhibiting microglial nucleotide-binding domain (NOD)-like receptor protein 3 (NLRP3) signaling, but this possibility needs to be further investigated. In addition to the resident microglial activation, the infiltration of circulating monocytes/macrophages is considered to play a vital role in post-stroke neuroinflammation [57]. Details regarding the mechanisms that underlie the effects of CORM-3 on microglia and macrophages after ischemic stroke require additional exploration.

Normally, the $\mathrm{BBB}$ protects the brain from toxic substances. BBB disruption is a crucial event in the pathogenesis of acute ischemic stroke that leads to cerebral edema, brain hemorrhage, and neuronal death [7]. Previous data suggest that overexpression of metalloproteinases, especially MMP-9, after ischemic stroke 


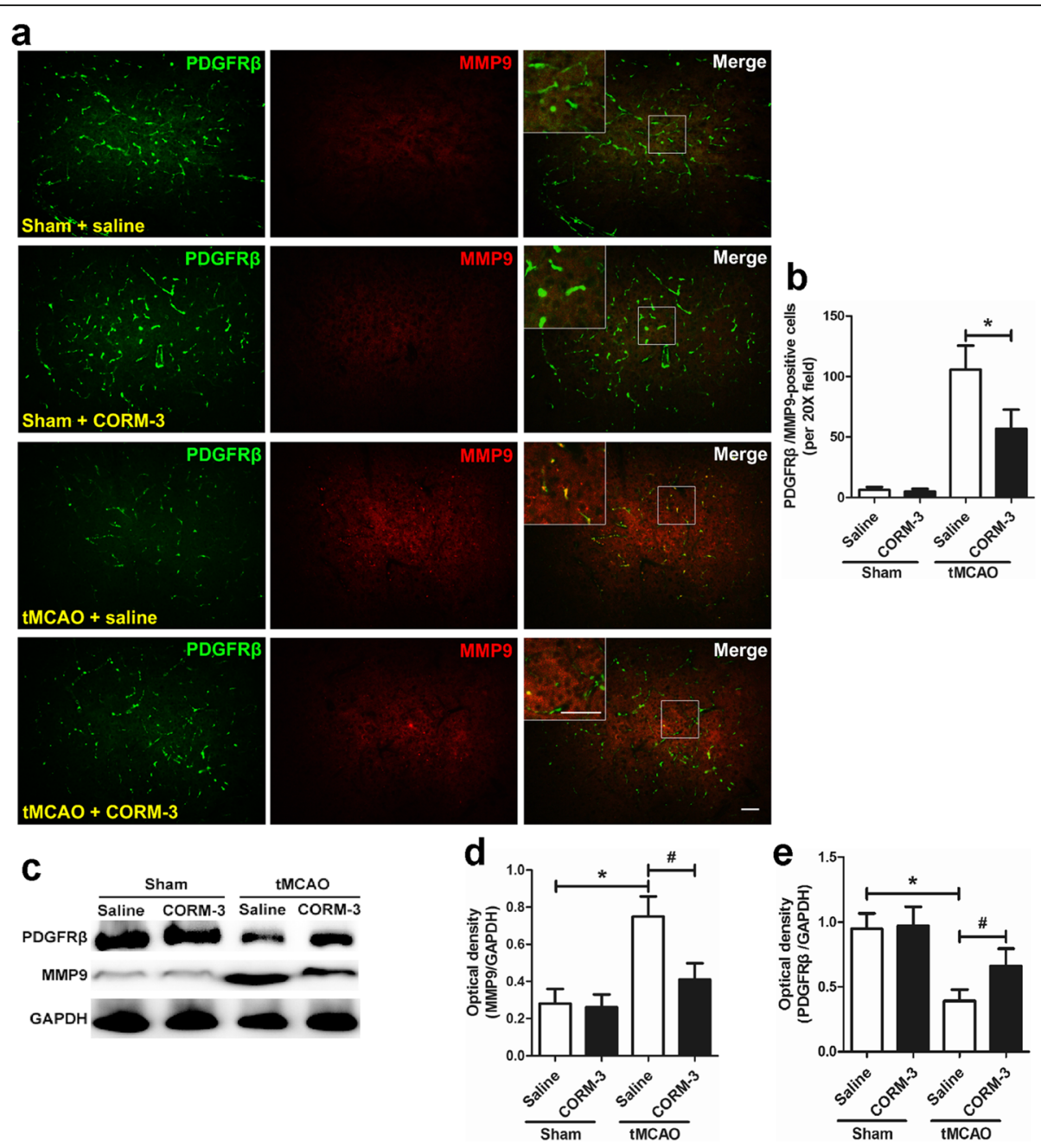

Fig. 6 Effects of CORM-3 on the expression of PDGFRß and MMP-9 on day 3 after ischemic stroke. a Representative images show double immunofluorescence staining of PDGFRß/MMP-9-positive cells in peri-infarction zones. Insets show high-magnification images of the boxed areas. Scale bar $=50 \mu \mathrm{m}$. b Quantification of the double immunofluorescence staining ( ${ }^{*} p<0.05, n=8$ per group). $\mathbf{c}$ Representative Western blot of PDGFR $\beta$ and MMP-9 expression in the ipsilateral tissue of each group. $\mathbf{d}$, e Quantification of the Western blot analysis $\left({ }^{*} p<0.05\right.$ vs. Sham + saline group, ${ }^{\#} p<0.05$ vs. tMCAO + CORM-3 group, $n=10$ per group). Data are shown as mean \pm SD

disrupts the $\mathrm{BBB}$ by degrading the tight junctions and basal lamina proteins [24, 60-63]. Furthermore, a recent study showed that pericytes, a key component of the $\mathrm{BBB}$, contribute to $\mathrm{BBB}$ disruption in the capillary bed during acute ischemic stroke, with rapid MMP-9 activation at pericyte somata before capillary leakage [64]. In a mouse model of traumatic brain injury, CORM-3 was shown to reduce pericyte death and MMP-9 expression at pericyte somata [24]. However, the effect of CORM-3 on BBB disruption after ischemic stroke remains unknown. In this study, we showed that CORM-3 treatment reduced Evans blue leakage and brain edema, indicating that it can reduce BBB permeability in mice after tMCAO. The administration of CORM-3 increased the expression of PDGFR $\beta$, ZO- 1 , and laminin and decreased the expression of MMP-9, indicating that it can protect pericytes, tight junction proteins, and matrix proteins after tMCAO. These results suggest that CORM-3 can potentially protect $\mathrm{BBB}$ integrity from ischemic stroke injury. Although we showed that CORM-3 decreased MMP-9 expression after ischemia, its effect on MMP-9 function would be better supported by gelatin gel zymography assessment [65]. Considering the peak concentration of reactive oxygen species (ROS) during reperfusion [66], we hypothesize that CORM-3 may rescue pericytes after tMCAO by stabilizing the ROS/hypoxia-inducible factor- $1 \alpha$ axis, leading to microvascular stabilization. Although studies have shown that CORM-3-derived $\mathrm{CO}$ may be a potent enhancer of angiogenesis in vitro [67], and pericytes may contribute to post-stroke angiogenesis [68-70], it would be interesting to identify the direct effect of CORM-3 on 
endothelial cells after ischemic stroke, and the indirect effect of CORM-3 on angiogenesis, for example whether CORM-3 affects pericyte-endothelial cell crosstalk after stroke.

One limitation of our study is that we administered CORM-3 only at the time of reperfusion by way of retro-orbital injection. The effects of CORM-3 administrations at different time points and by different routes should be further investigated. Additionally, microscopic analysis of the brains was made only on day 3 after tMCAO, which may be sufficient to support our conclusion, but longitudinal observations, such as on days 7 , 14 , and 21 , are needed to clarify the mechanism by which CORM-3 promotes post-stroke recovery. It would be interesting to study the mechanism by which CORM-3 treatment suppresses microglial activation in the ischemic brain and to determine whether CORM-3 affects newly generated microvessels. Identification of the long-term effects of CORM-3 on ischemic stroke will provide better support for the potential therapeutic value of the CORMs.

\section{Conclusions}

In conclusion, we showed that CORM-3 treatment at the time of reperfusion exerts beneficial effects on ischemiareperfusion brain injury by suppressing neuroinflammation and alleviating BBB disruption. Our findings support the premise that CORM-derived $\mathrm{CO}$ may potentially be applied in the treatment of ischemic stroke.

\section{Abbreviations}

BBB: Blood-brain barrier; BSA: Bovine serum albumin; CO: Carbon monoxide; $\mathrm{COHb}$ : Carboxyhemoglobin; CORM-3: Carbon monoxide-releasing molecule-3; DAPI: 4', 6-Diamidino-2-phenylindole; Iba-1: Ionized calcium-binding adapter molecule-1; IL-1 $\beta$ : Interleukin 1 $\beta$; MAP 2: Microtubule-associated protein 2; MMP-9: Matrix metalloproteinase-9; NeuN: Neuronal nuclear antigen; PBS: Phosphate-buffered saline; PDGFR- $\beta$ : Platelet-derived growth factor receptor- $\beta$; TBS: Tris-buffered saline; tMCAO: Transient middle cerebral artery occlusion; TNF-a: Tumor necrosis factor-a; TTC: 2,3,5-Triphenyltetrazolium chloride

\section{Funding \\ This work was supported by grants from the National Natural Science Foundation of China (81571137, 81771247, U1704166), the Henan Province Science and Technology Cooperation Projects (No. 182106000061), the American Heart Association Grant-in-Aid (17GRNT33660766), the National Institutes of Health (R01NS078026, R01AT007317, R56NS096549, R21NS101614, R21NS102899, and UG3NS106937), and a Stimulating and Advancing ACCM Research (StAAR) grant from the Department of Anesthesiology and Critical Care Medicine, Johns Hopkins University.}

\section{Availability of data and materials}

The datasets supporting the conclusions of this article are included within the article.

\section{Authors' contributions}

$J W, D Z$, and JW designed the study. JW, DZ, ZF, YG, XL, JM, and SL performed the experiments and analyzed the data. JW, DZ, XF, YL, NL, and $X C$ managed the literature searches and figure drawing. JW, DZ, MH, QY, and JW wrote or contributed to the writing of the manuscript. All authors have approved the final version of the manuscript.

\section{Ethics approval}

We carried out the study in accordance with the recommendations of the Guidelines on the Care and Use of Animals for Scientific Purpose (National Advisory Committee for Laboratory Animal Research), and all animal procedures were approved by the Animal Care and Use Committee of Zhengzhou University.

\section{Consent for publication}

Not applicable.

\section{Competing interests}

The authors declare that they have no competing interests.

\section{Publisher's Note}

Springer Nature remains neutral with regard to jurisdictional claims in published maps and institutional affiliations.

\section{Author details}

${ }^{1}$ Department of Neurology, The First Affiliated Hospital of Zhengzhou University, Zhengzhou 450052, Henan, China. ${ }^{2}$ Department of Neurology, The Second Affiliated Hospital of Zhengzhou University, Zhengzhou 450014, Henan, China. ${ }^{3}$ Department of Anesthesiology/Critical Care Medicine, Johns Hopkins University, School of Medicine, Baltimore 21205, MD, USA. ${ }^{4}$ Department of Anatomy, College of Basic Medical Sciences, Zhengzhou University, Zhengzhou 450000, Henan, China. ${ }^{5}$ Department of Neurology, Xinqiao Hospital, Third Military Medical University, Chongqing 400037, China.

Received: 20 December 2017 Accepted: 14 June 2018

Published online: 21 June 2018

\section{References}

1. Li Y, Xu L, Zeng K, Xu Z, Suo D, Peng L, Ren T, Sun Z, Yang W, Jin X, Yang L. Propane-2-sulfonic acid octadec-9-enyl-amide, a novel PPARalpha/gamma dual agonist, protects against ischemia-induced brain damage in mice by inhibiting inflammatory responses. Brain Behav Immun. 2017;66:289-301.

2. Stonesifer C, Corey S, Ghanekar S, Diamandis Z, Acosta SA, Borlongan CV. Stem cell therapy for abrogating stroke-induced neuroinflammation and relevant secondary cell death mechanisms. Prog Neurobiol. 2017;158:94-131.

3. Wu MH, Huang CC, Chio CC, Tsai KJ, Chang CP, Lin NK, Lin MT. Inhibition of peripheral TNF-alpha and downregulation of microglial activation by alphalipoic acid and etanercept protect rat brain against ischemic stroke. Mol Neurobiol. 2016;53:4961-71.

4. Mizuma A, Yenari MA. Anti-inflammatory targets for the treatment of reperfusion injury in stroke. Front Neurol. 2017:8:467.

5. Lan X, Han X, Li Q, Yang QW, Wang J. Modulators of microglial activation and polarization after intracerebral haemorrhage. Nat Rev Neurol. 2017;13:420-33.

6. Wang W, Li M, Chen Q, Wang J. Hemorrhagic transformation after tissue plasminogen activator reperfusion therapy for ischemic stroke: mechanisms, models, and biomarkers. Mol Neurobiol. 2015:52:1572-9.

7. Jiang X, Andjelkovic AV, Zhu L, Yang T, Bennett MVL, Chen J, Keep RF, Shi Y. Blood-brain barrier dysfunction and recovery after ischemic stroke. Prog Neurobiol. 2017;163:144-71.

8. Tang X, Liu K, Hamblin MH, Xu Y, Yin KJ. Genetic deletion of Kruppel-like factor 11 aggravates ischemic brain injury. Mol Neurobiol. 2017;55(4):2911-21.

9. Li Q, Han X, Lan X, Hong X, Li Q, Gao Y, Luo T, Yang Q, Koehler RC, Zhai Y, et al. Inhibition of tPA-induced hemorrhagic transformation involves adenosine A2b receptor activation after cerebral ischemia. Neurobiol Dis. 2017;108:173-82.

10. Motterlini R, Otterbein LE. The therapeutic potential of carbon monoxide. Nat Rev Drug Discov. 2010;9:728-43.

11. Queiroga CS, Vercelli A, Vieira HL. Carbon monoxide and the CNS: challenges and achievements. Br J Pharmacol. 2015;172:1533-45.

12. Wu L, Wang R. Carbon monoxide: endogenous production, physiological functions, and pharmacological applications. Pharmacol Rev. 2005;57:585-630.

13. Zhang Z, Song Y, Zhang Z, Li D, Zhu H, Liang R, Gu Y, Pang Y, Qi J, Wu H, Wang J. Distinct role of heme oxygenase- 1 in early- and late-stage intracerebral hemorrhage in 12-month-old mice. J Cereb Blood Flow Metab. 2017;37:25-38.

14. Wang J, Dore S. Heme oxygenase-1 exacerbates early brain injury after intracerebral haemorrhage. Brain. 2007;130:1643-52. 
15. Szabo C. Gasotransmitters in cancer: from pathophysiology to experimental therapy. Nat Rev Drug Discov. 2016;15:185-203.

16. Otterbein LE, Bach FH, Alam J, Soares M, Tao Lu H, Wysk M, Davis RJ, Flavell RA, Choi AM. Carbon monoxide has anti-inflammatory effects involving the mitogen-activated protein kinase pathway. Nat Med. 2000;6:422-8.

17. Brouard S, Otterbein LE, Anrather J, Tobiasch E, Bach FH, Choi AM, Soares MP. Carbon monoxide generated by heme oxygenase 1 suppresses endothelial cell apoptosis. J Exp Med. 2000;192:1015-26.

18. Schatzschneider U. Novel lead structures and activation mechanisms for CO-releasing molecules (CORMs). Br J Pharmacol. 2015;172:1638-50.

19. Guo Y, Stein AB, Wu WJ, Tan W, Zhu X, Li QH, Dawn B, Motterlini R, Bolli R. Administration of a CO-releasing molecule at the time of reperfusion reduces infarct size in vivo. Am J Physiol Heart Circ Physiol. 2004;286:H1649-53.

20. Seixas JD, Santos MF, Mukhopadhyay A, Coelho AC, Reis PM, Veiros LF, Marques AR, Penacho N, Goncalves AM, Romao MJ, et al. A contribution to the rational design of $\mathrm{Ru}(\mathrm{CO}) 3 \mathrm{Cl} 2 \mathrm{~L}$ complexes for in vivo delivery of $\mathrm{CO}$. Dalton Trans. 2015;44:5058-75.

21. Yoon YE, Lee KS, Lee YJ, Lee HH, Han WK. Renoprotective effects of carbon monoxide-releasing molecule 3 in ischemia-reperfusion injury and cisplatininduced toxicity. Transplant Proc. 2017;49:1175-82.

22. Yabluchanskiy A, Sawle P, Homer-Vanniasinkam S, Green CJ, Foresti R, Motterlini R. CORM-3, a carbon monoxide-releasing molecule, alters the inflammatory response and reduces brain damage in a rat model of hemorrhagic stroke. Crit Care Med. 2012;40:544-52.

23. Ruan Y, Wang L, Zhao Y, Yao Y, Chen S, Li J, Guo H, Ming C, Chen S, Gong F, Chen G. Carbon monoxide potently prevents ischemia-induced highmobility group box 1 translocation and release and protects against lethal renal ischemia-reperfusion injury. Kidney Int. 2014;86:525-37.

24. Choi YK, Maki T, Mandeville ET, Koh SH. Dual effects of carbon monoxide on pericytes and neurogenesis in traumatic brain injury. Nat Med. 2016;22:1335-41.

25. Jamal Uddin M, Joe Y, Kim SK, Oh Jeong S, Ryter SW, Pae HO, Chung HT. IRG1 induced by heme oxygenase-1/carbon monoxide inhibits LPSmediated sepsis and pro-inflammatory cytokine production. Cell Mol Immunol. 2016;13:170-9.

26. Chatterjee PK. Water-soluble carbon monoxide-releasing molecules: helping to elucidate the vascular activity of the 'silent killer'. Br J Pharmacol. 2004;142:391-3.

27. Zhang W, Tao A, Lan T, Cepinskas G, Kao R, Martin CM, Rui T. Carbon monoxide releasing molecule-3 improves myocardial function in mice with sepsis by inhibiting NLRP3 inflammasome activation in cardiac fibroblasts. Basic Res Cardiol. 2017;112:16.

28. Tsai MH, Lee CW, Hsu LF, Li SY, Chiang YC, Lee MH, Chen CH, Liang HF, How JM, Chang PJ, et al. CO-releasing molecules CORM2 attenuates angiotensin II-induced human aortic smooth muscle cell migration through inhibition of ROS/L-6 generation and matrix metalloproteinases-9 expression. Redox Biol. 2017;12:377-88.

29. Wang J, Liu X, Lu H, Jiang C, Cui X, Yu L, Fu X, Li Q, Wang J. CXCR4(+)CD45(-) BMMNC subpopulation is superior to unfractionated BMMNCs for protection after ischemic stroke in mice. Brain Behav Immun. 2015;45:98-108.

30. Wang J, Lu Z, Fu X, Zhang D, Yu L, Li N, Gao Y, Liu X, Yin C, Ke J, et al. Alpha-7 nicotinic receptor signaling pathway participates in the neurogenesis induced by ChAT-positive neurons in the subventricular zone. Transl Stroke Res. 2017;8:484-93.

31. Wang J, Fu X, Zhang D, Yu L, Lu Z, Gao Y, Liu X, Man J, Li S, Li N, et al. Effects of crenolanib, a nonselective inhibitor of PDGFR, in a mouse model of transient middle cerebral artery occlusion. Neuroscience. 2017;364:202-11.

32. Cheng T, Wang W, Li Q, Han X, Xing J, Qi C, Lan X, Wan J, Potts A, Guan F, Wang J. Cerebroprotection of flavanol (-)-epicatechin after traumatic brain injury via Nrf2-dependent and -independent pathways. Free Radic Biol Med. 2016;92:15-28.

33. Yardeni T, Eckhaus M, Morris HD, Huizing M, Hoogstraten-Miller S. Retro-orbital injections in mice. Lab Anim (NY). 2011;40:155-60.

34. Pan LN, Zhu W, Li Y, Xu XL, Guo LJ, Lu Q, Wang J. Astrocytic Toll-like receptor 3 is associated with ischemic preconditioning-induced protection against brain ischemia in rodents. PLoS One. 2014;9:e99526.

35. Yang J, Li Q, Wang Z, Qi C, Han X, Lan X, Wan J, Wang W, Zhao X, Hou Z, et al. Multimodality MRl assessment of grey and white matter injury and blood-brain barrier disruption after intracerebral haemorrhage in mice. Sci Rep. 2017;7:40358.

36. Kim GW, Gasche Y, Grzeschik S, Copin JC, Maier CM, Chan PH Neurodegeneration in striatum induced by the mitochondrial toxin 3nitropropionic acid: role of matrix metalloproteinase-9 in early blood-brain barrier disruption? J Neurosci. 2003;23:8733-42.
37. Jiang C, Zuo F, Wang Y, Lu H, Yang Q, Wang J. Progesterone changes VEGF and BDNF expression and promotes neurogenesis after ischemic stroke. Mol Neurobiol. 2017;54:571-81.

38. Zhu W, Gao Y, Wan J, Lan X, Han X, Zhu S, Zang W, Chen X, Ziai W, Hanley $D F$, et al. Changes in motor function, cognition, and emotion-related behavior after right hemispheric intracerebral hemorrhage in various brain regions of mouse. Brain Behav Immun. 2018;69:568-81.

39. Han X, Lan X, Li Q, Gao Y, Zhu W, Cheng T, Maruyama T, Wang J. Inhibition of prostaglandin E2 receptor EP3 mitigates thrombin-induced brain injury. J Cereb Blood Flow Metab. 2016;36:1059-74.

40. Wang J, Fu X, Zhang D, Yu L, Li N, Lu Z, Gao Y, Wang M, Liu X, Zhou C, et al. ChAT-positive neurons participate in subventricular zone neurogenesis after middle cerebral artery occlusion in mice. Behav Brain Res. 2017;316:145-51.

41. Wu H, Wu T, Xu X, Wang J, Wang J. Iron toxicity in mice with collagenaseinduced intracerebral hemorrhage. J Cereb Blood Flow Metab. 2011;31:1243-50.

42. Nobre LS, Jeremias H, Romao CC, Saraiva LM. Examining the antimicrobial activity and toxicity to animal cells of different types of CO-releasing molecules. Dalton Trans. 2016;45:1455-66.

43. Farrugia G, Szurszewski JH. Carbon monoxide, hydrogen sulfide, and nitric oxide as signaling molecules in the gastrointestinal tract. Gastroenterology. 2014;147:303-13.

44. Gomperts E, Belcher JD, Otterbein LE, Coates TD, Wood J, Skolnick BE, Levy $\mathrm{H}$, Vercellotti GM. The role of carbon monoxide and heme oxygenase in the prevention of sickle cell disease vaso-occlusive crises. Am J Hematol. 2017; 92:569-82.

45. Zeynalov E, Dore $S$. Low doses of carbon monoxide protect against experimental focal brain ischemia. Neurotox Res. 2009;15:133-7.

46. Wang B, Cao W, Biswal S, Dore S. Carbon monoxide-activated Nrf2 pathway leads to protection against permanent focal cerebral ischemia. Stroke. 2011; 42:2605-10.

47. Abid S, Houssaini A, Mouraret N, Marcos E, Amsellem V, Wan F, DuboisRande JL, Derumeaux G, Boczkowski J, Motterlini R, Adnot S. P21-dependent protective effects of a carbon monoxide-releasing molecule-3 in pulmonary hypertension. Arterioscler Thromb Vasc Biol. 2014;34:304-12.

48. Zhao C, Deng W, Gage FH. Mechanisms and functional implications of adult neurogenesis. Cell. 2008;132:645-60.

49. Ernst A, Alkass K, Bernard S, Salehpour M, Perl S, Tisdale J, Possnert G, Druid H, Frisen J. Neurogenesis in the striatum of the adult human brain. Cell. 2014;156:1072-83.

50. Nayak D, Roth TL, McGavern DB. Microglia development and function. Annu Rev Immunol. 2014;32:367-402.

51. Ginhoux F, Prinz M. Origin of microglia: current concepts and past controversies. Cold Spring Harb Perspect Biol. 2015;7:a020537.

52. Zhang Z, Zhang Z, Lu H, Yang Q, Wu H, Wang J. Microglial polarization and inflammatory mediators after intracerebral hemorrhage. Mol Neurobiol. 2017;54: 1874-86.

53. Lambertsen $\mathrm{KL}$, Biber $\mathrm{K}$, Finsen B. Inflammatory cytokines in experimental and human stroke. J Cereb Blood Flow Metab. 2012;32:1677-98.

54. Sobowale OA, Parry-Jones AR, Smith CJ, Tyrrell PJ, Rothwell NJ, Allan SM. Interleukin-1 in stroke: from bench to bedside. Stroke. 2016;47:2160-7.

55. Bani-Hani MG, Greenstein D, Mann BE, Green CJ, Motterlini R. Modulation of thrombin-induced neuroinflammation in BV-2 microglia by carbon monoxide-releasing molecule 3. J Pharmacol Exp Ther. 2006;318:1315-22.

56. Li Q, Wan J, Lan X, Han X, Wang Z, Wang J. Neuroprotection of brainpermeable iron chelator VK-28 against intracerebral hemorrhage in mice. J Cereb Blood Flow Metab. 2017:37:3110-23.

57. Xiong XY, Liu L, Yang QW. Functions and mechanisms of microglia/ macrophages in neuroinflammation and neurogenesis after stroke. Prog Neurobiol. 2016;142:23-44.

58. Liesz A, Dalpke A, Mracsko E, Antoine DJ, Roth S, Zhou W, Yang H, Na SY, Akhisaroglu M, Fleming T, et al. DAMP signaling is a key pathway inducing immune modulation after brain injury. J Neurosci. 2015;35:583-98.

59. Burguillos MA, Svensson M, Schulte T, Boza-Serrano A, Garcia-Quintanilla A, Kavanagh E, Santiago M, Viceconte N, Oliva-Martin MJ, Osman AM, et al. Microglia-secreted galectin-3 acts as a toll-like receptor 4 ligand and contributes to microglial activation. Cell Rep. 2015;10:1626-38.

60. Turner RJ, Sharp FR. Implications of MMP9 for blood brain barrier disruption and hemorrhagic transformation following ischemic stroke. Front Cell Neurosci. 2016;10:56

61. Rempe RG, Hartz AM, Bauer B. Matrix metalloproteinases in the brain and blood-brain barrier: versatile breakers and makers. J Cereb Blood Flow Metab. 2016;36:1481-507. 
62. Chaturvedi M, Kaczmarek L. Mmp-9 inhibition: a therapeutic strategy in ischemic stroke. Mol Neurobiol. 2014;49:563-73.

63. Wu H, Wu T, Han X, Wan J, Jiang C, Chen W, Lu H, Yang Q, Wang J. Cerebroprotection by the neuronal PGE2 receptor EP2 after intracerebral hemorrhage in middle-aged mice. J Cereb Blood Flow Metab. 2017;37:39-51.

64. Underly RG, Levy M, Hartmann DA. Pericytes as inducers of rapid, matrix metalloproteinase-9-dependent capillary damage during ischemia. J Neurosci. 2017:37:129-40.

65. Han X, Zhao X, Lan X, Li Q, Gao Y, Liu X, Wan J, Yang Z, Chen X, Zang W, et al. 20-HETE synthesis inhibition promotes cerebral protection after intracerebral hemorrhage without inhibiting angiogenesis. J Cereb Blood Flow Metab. 2018;2018 https://doi.org/10.1177/0271678X18762645.

66. Gursoy-Ozdemir Y, Can A, Dalkara T. Reperfusion-induced oxidative/nitrative injury to neurovascular unit after focal cerebral ischemia. Stroke. 2004;35: 1449-53.

67. Li Volti G, Sacerdoti D, Sangras B, Vanella A, Mezentsev A, Scapagnini G, Falck JR, Abraham NG. Carbon monoxide signaling in promoting angiogenesis in human microvessel endothelial cells. Antioxid Redox Signal. 2005:7:704-10.

68. Winkler EA, Bell RD, Zlokovic BV. Central nervous system pericytes in health and disease. Nat Neurosci. 2011;14:1398-405.

69. Zechariah A, ElAli A, Hagemann N, Jin F, Doeppner TR, Helfrich I, Mies G, Hermann DM. Hyperlipidemia attenuates vascular endothelial growth factorinduced angiogenesis, impairs cerebral blood flow, and disturbs stroke recovery via decreased pericyte coverage of brain endothelial cells. Arterioscler Thromb Vasc Biol. 2013;33:1561-7.

70. Yang S, Jin H, Zhu Y, Wan Y, Opoku EN, Zhu L, Hu B. Diverse functions and mechanisms of pericytes in ischemic stroke. Curr Neuropharmacol. 2017;15: 892-905.

Ready to submit your research? Choose BMC and benefit from:

- fast, convenient online submission

- thorough peer review by experienced researchers in your field

- rapid publication on acceptance

- support for research data, including large and complex data types

- gold Open Access which fosters wider collaboration and increased citations

- maximum visibility for your research: over $100 \mathrm{M}$ website views per year

At BMC, research is always in progress.

Learn more biomedcentral.com/submissions 